\title{
Alkyl-glycerophosphate-mediated C-C motif chemokine 2 secretion induces oxidative stress via increased PPAR $\gamma$ activation in human umbilical vein endothelial cells
}

Tamotsu Tsukahara $^{\mathrm{a}^{*}}$ and Shuhei Yamagishi ${ }^{\mathrm{a}}$ and Yoshikazu Matsuda ${ }^{\mathrm{b}}$ and Hisao Haniu ${ }^{\mathrm{c}}$

a Department of Pharmacology and Therapeutic Innovation, Nagasaki University Graduate School of Biomedical Sciences, 1-14 Bunkyo-machi, Nagasaki 852-8521, Japan

${ }^{\mathrm{b} C l i n i c a l}$ Pharmacology Educational Center, Nihon Pharmaceutical University, Ina-machi, Saitama 362-0806, Japan

'Institute for Biomedical Sciences, Shinshu University Interdisciplinary Cluster for Cutting Edge Research 3-1-1 Asahi, Matsumoto, Nagano 390-8621, Japan

Running title: $A G P$ and chemokine

"To whom correspondence should be addressed: Tamotsu Tsukahara

Department of Pharmacology and Therapeutic Innovation, Nagasaki University Graduate School of Biomedical Sciences, 1-14 Bunkyo-machi, Nagasaki 852-8521, Japan

E-mail: ttamotsu@nagasaki-u.ac.jp

\begin{abstract}
Abbreviations:
PPAR $\gamma$ : peroxisome proliferator-activator receptor gamma; AGP: alkyl-glycerophosphate; FBS: fetal bovine serum; SDS: sodium dodecyl sulfate; TBS-T: Tris-buffered saline containing Tween 20; RT-PCR: quantitative real-time reverse transcription polymerase chain reaction; siRNA: small-interfering RNA; DMEM: Dulbecco's modified Eagle's medium; ELISA, enzyme-linked immunosorbent assay; PBS: phosphate-buffered saline
\end{abstract}




\begin{abstract}
We previously showed that an alkyl-ether analog of lysophosphatidic acid, AGP (alkylglycerophosphate), accumulates in human atherosclerotic plaques and is a potent agonist of peroxisome proliferator-activated receptor-gamma (PPAR $\gamma)$. On the other hand, cyclic phosphatidic acid (cPA), similar in structure to AGP, can negatively regulate PPAR $\gamma$. However, in this study, cPA had no effect on the expression and secretion of C-C motif chemokine 2 (CCL-2), a chemokine that is also linked to inflammatory responses and atherosclerosis. We showed that AGP enhances CCL-2 mRNA expression and secretion in a dose-dependent manner. Furthermore, oxidative stress plays a major role in the pathology of cardiovascular diseases; we showed that AGP triggers ROS generation and lipid peroxidation and that ROS and 8-isoprostane generation can be suppressed by a PPAR $\gamma$ antagonist. These results suggest that an imbalance of the PPAR $\gamma$ agonist-antagonist equilibrium is involved in changes in cellular functions, including ROS generation and lipid peroxidation.
\end{abstract}

Keywords: AGP; PPAR $\gamma$; CCL-2; ROS; peroxidation 


\section{Introduction}

Inflammation and oxidative stress are major factors involved in the pathogenesis of cardiovascular diseases (Garcia et al. 2017). We previously reported that an alkyl-ether analog of lysophosphatidic acid, AGP, accumulates in human atherosclerotic plaques and is a potent agonist of peroxisome proliferator-activated receptor-gamma (PPAR $\gamma$ ) (Tsukahara et al. 2013). Oxidative stress and lipid peroxidation are well-known contributors to disease pathogenesis. Numerous lines of evidence have linked PPAR $\gamma$ activation with inhibiting inflammation, COX, and eNOS and inducing anti-oxidant responses (Kvandova et al. 2016). However, whether AGP is deleterious or protective via PPAR gamma agonism remains unclear. AGP has a higher potency for PPAR $\gamma$ activation than LPA (Tsukahara et al. 2006). Binding studies using the PPAR $\gamma$ ligand-binding domain showed that binding of the AGP was similar to that of the TZD rosiglitazone. We previously identified cyclic phosphatidic acid (cPA) as an endogenous PPAR $\gamma$ antagonist generated by phospholipase D2 (PLD2) (Tsukahara et al. 2010). These observations suggest that activation of PPAR $\gamma$ is likely to lead to a complex cellular response. A recent study indicated that PPAR $\gamma$ plays important roles in the type- 2 immune responses which are well-established drivers of chronic inflammatory diseases such as endothelial dysfunction, as evidenced by PPAR $\gamma$ expression in inflammatory cells, such as dendritic cells, and T cells (Nobs et al. 2017). These results suggest that PPAR $\gamma$ activation is an important regulatory factor in vascular inflammation (Chandra et al. 2017). Elevated levels of pro-inflammatory cytokines and chemokines are hallmarks of metabolic syndrome (Volp et al. 2008). Chemokines are also involved in the pathogenesis of atherosclerosis by promoting the directed migration of inflammatory cells (Reape \& Groot 1999). Our previous study reported that LPA enhanced $C C L-2$ mRNA expression and protein secretion in a dosedependent manner in C2C12 myoblasts (Tsukahara \& Haniu 2012). CCL-2 is a relatively basic $8.7-\mathrm{kDa}$ and is a heparin-binding $\mathrm{C}-\mathrm{C}$ chemokine produced by monocytes. It is expressed in various tissues, including endothelial, bronchial, epithelial, and smooth muscle cells (De Rossi et al. 2000). CCL-2, an important chemokine, has a critical role in the migration of bone marrow-derived and tissue-resident cells to sites of inflammation 
(Deshmane et al. 2009). There is evidence for the importance of CCL-2 in atherosclerosis in humans (Harrington 2000). For example, $C C L-2$ mRNA expression has been detected in endothelial cells in atherosclerotic arteries of patients (Lin et al. 2014). The expression level of CCL-2 is upregulated after exposure to pro-inflammatory stimuli and tissue injury, which are associated with atherosclerotic lesions (Lin et al. 2014). Furthermore, reactive oxygen species (ROS) are key mediators of signaling pathways that underlie vascular inflammation in atherogenesis (Mittal et al. 2014). Lipid peroxidation occurs naturally at low levels in the body and is mainly mediated by reactive oxygen species (Mylonas \& Kouretas 1999). A previous study suggested that LPA produces an increase in lipid peroxidation in the pathogenesis of atherosclerotic vascular disease (Shao \& Heinecke 2009). Lectin-like oxidized low-density lipoprotein is involved in endothelial dysfunction and injury upon stimulation by AGP (Zhang et al. 2004). Thus, oxidative stress and lipid peroxidation contribute substantially to the pathogenesis of cardiovascular diseases. Therefore, wellcharacterized vascular models with human relevance are needed for basic research. Here, we used human umbilical vein endothelial cells (HUVECs) to study the role of AGP-mediated PPAR $\gamma$ activation, oxidative stress, and peroxidation in the regulation of cellular function.

\section{Results}

Analysis of endogenous PPAR $\gamma$ expression and activation in HUVECs

Two PPAR $\gamma$ isoforms, PPAR $\gamma_{1}$ and PPAR $\gamma_{2}$, which originate from alternative splicing, have been detected in mammals. As shown in Fig. 1A, we first examined the expression of $P P A R \gamma 1$ and $P P A R \gamma 2$ mRNA in HUVECs. In contrast to PPAR 1 mRNA expression, $P P A R \gamma 2$ expression was low in HUVECs. PPAR $\gamma_{1}$ and PPAR $\gamma_{2}$ protein expression levels also differed, and were consistent with the differences in mRNA levels (Fig. 1B). The protein had a molecular mass of approximately $50 \mathrm{kDa}$, consistent with the reported value for the PPAR $\gamma 1$ protein (Tontonoz et al. 1994). Next, to determine if PPAR $\gamma$ expressed in HUVECs is functional, we transfected cells with a pGL3-PPRE-acyl-CoA oxidase luciferase reporter plasmid. Luciferase activity in cells treated with $0.1,1$, and $10 \mu \mathrm{M}$ rosiglitazone, a full 
PPAR $\gamma$ agonist, as a positive control for $24 \mathrm{~h}$ was approximately 1.8 -fold higher $(0.1 \mu \mathrm{M})$ than that in vehicle (DMSO)-treated cells. Furthermore, luciferase activity increased in HUVECs after exposure to AGP in a dose-dependent manner, and this activation was attenuated by the PPAR $\gamma$ antagonists T0070907 and cPA. The latter, cPA, has been reported to inhibit PPAR $\gamma$, demonstrating the opposite effect to that of AGP (Tsukahara et al. 2006) (Tsukahara et al. 2010). These results together suggest that rosiglitazone and AGP can activate the PPRE-ACox-Luc reporter gene depending on the expression of PPAR $\gamma$ in HUVECs.

AGP-mediated PPAR activation increased CCL-2 expression and secretion in HUVECS Endothelial cells produce a variety of cytokines and chemokines (Turner et al. 2014). To examine the modulation of CCL-2 secretion from endothelial cells after AGP treatment, HUVECs were grown to $80 \%$ confluence. After treatment with AGP, cytokine responses in HUVECs were analyzed based on mRNA expression. First, HUVECs were stimulated with AGP $(1,3$, and $10 \mu \mathrm{M})$ and LPS $(10 \mathrm{ng} / \mathrm{mL})$ as a positive control. Total RNA was isolated and subjected to reverse transcription RT-PCR to evaluate the mRNA levels of $C C L-2$. A recent study has suggested a potential regulatory role of PPAR $\gamma$-dependent CCL-2 expression and production in vascular diseases (Verma \& Szmitko 2006) (Panzer et al. 2002). As shown in Fig.2A, AGP increased CCL-2 mRNA expression in HUVECs treated with AGP for $24 \mathrm{~h}$ at 1,3 , and $10 \mu \mathrm{M}$, and this effect was attenuated by T0070907 and cPA. These results further confirmed the role of AGP in the induction of CCL-2 in HUVECs. Furthermore, to determine whether AGP-induced CCL-2 production is dependent on PPAR $\gamma$, HUVECs were treated with PPAR $\gamma$ siRNA. As shown in Fig. 2B, a real-time PCR analysis showed that PPAR $\gamma$ mRNA expression levels in siRNA-transfected cells were reduced by $90 \%$ compared to the expression levels in control siRNA-transfected cells. A western blot analysis using an antiPPAR $\gamma$ antibody showed that PPAR $\gamma$ knockdown in HUVECs was effective (Fig. 2C). CCL-2 concentrations in the clarified culture supernatants were then measured by ELISA. The induction of CCL-2 production by AGP was inhibited in PPAR $\gamma$ siRNA-transfected HUVECs 
(Fig. 2D, and E). These results confirmed that AGP-induced PPAR $\gamma$ activation resulted in the increase of CCL-2 production in HUVECs.

\section{AGP-mediated PPAR activation stimulates ROS generation in HUVECS}

Recent studies have suggested that ROS are important intracellular signaling messengers linking cell dysfunction to subsequent inflammatory responses (Mittal et al. 2014). We examined whether AGP, which generates oxidative stress via CCL-2 secretion, could enhance ROS generation and oxidation products in HUVECs. As shown in Fig.3A, interestingly, ROS production in HUVECs was significantly increased upon treatment with AGP in a dosedependent manner, and this secretion was attenuated by the PPAR $\gamma$ antagonists T0070907 and cPA. Our study also clearly demonstrated that 3-tert-butyl-4-hydroxyanisole (BHA) blocked AGP-induced ROS generation. These results confirmed that AGP-induced PPAR $\gamma$ activation increased ROS generation in HUVECs. Reduced glutathione (GSH) is a major antioxidant and protects cells from oxidative stress by scavenging peroxides in the cytosol and mitochondria (Wang \& Tabas 2014). Oxidative stress can result in the depletion of intracellular GSH (Wu et al. 2004). In this study, AGP depleted intracellular GSH in a timedependent manner (Fig. 3B). The exposure of cells to AGP for 60 min led to intracellular GSH depletion of about $50 \%$ compared to levels in the control, and this depletion was inhibited by T0070907 and cPA. These results suggest that the depletion of GSH following AGP treatment may be due to an increase in PPAR $\gamma$-mediated ROS generation. On the other hand, PPAR $\gamma$ antagonists protect the cells against oxidative stress-mediated CCL-2 secretion through reducing ROS levels.

The AGP-PPAR $\gamma$-CCL-2 axis mediated 8-isoprostane generation in HUVECS

ROS induces lipid peroxidation and disrupts the membrane lipid bilayer arrangement, potentially increasing tissue permeability (Girotti 1985). Accurate biomarkers of lipid peroxidation are 8-isoprostanes formed by the peroxidation of arachidonic acid (Kaviarasan et 
al. 2009); upon oxidation, they combine with oxygen to produce superoxide anions. ROS levels influence the production of 8-isoprostane, affecting the regulation of cellular and systemic oxidative stress (Davies \& Roberts 2011). As shown in Fig.4A, AGP significantly increased 8-isoprostane production in a dose-dependent manner and this production was attenuated by the PPAR $\gamma$ antagonists T0070907 and cPA. We next performed an MTT assay to investigate HUVEC growth properties. As shown in Fig.4B, AGP induced a dosedependent increase in the proliferation of HUVECs and this proliferation was attenuated by the PPAR $\gamma$ antagonists T0070907 and cPA. These results confirmed that AGP-induced PPAR $\gamma$ activation resulted in an increase in the proliferation of HUVECs.

\section{Discussion}

Recent studies have suggested mechanistic links between PPAR $\gamma$ activation and oxidative stress. However, there are reports that support as well as refute this notion. In vascular endothelial cells, PPAR $\gamma$ ligands, 15-deoxy- $\Delta 12$, 14-prostaglandin $\mathrm{J}_{2}\left(15 \mathrm{~d}-\mathrm{PGJ}_{2}\right)$ or TZD drug, ciglitazone stimulated both activity and expression of superoxide dismutase (SOD) in HUVEC (Hwang et al. 2005). Another report suggested that agonist mediated-PPAR $\gamma$ activation uptake of oxidized low-density lipoprotein (oxLDL) in macrophages and promotes changes in gene expression induced by oxLDL generated by oxidative stress (Nagy et al. 1998). Activation of PPAR $\gamma$ in response to oxLDL has been shown to induce expression of the scavenger receptor cluster of differentiation $36(\mathrm{CD} 36)$ and the nuclear receptor LXR (Nagy et al. 1998). On the other hand, cyclic phosphatidic acid (cPA), one of nature's simplest phospholipids binds to and inhibits the PPAR $\gamma$ with nanomolar affinity and high specificity through stabilizing its interaction with the corepressor SMRT (Tsukahara et al. 2010). In this study, ROS production in HUVECs was significantly increased upon treatment with AGP in a dose-dependent manner, and this secretion was attenuated by the synthetic and natural PPAR $\gamma$ antagonists T0070907 and cPA. These results confirmed that AGP-induced PPAR $\gamma$ activation increased ROS generation in HUVECs. It has been reported that ROS and oxidative stress 
play critical roles in the pathogenesis of cardiovascular disease including diabetes (Giacco \& Brownlee 2010). It is likely that the cumulative impact of oxidative stress on PPAR $\gamma$

signaling in vascular endothelial cells are regulated not only by PPAR $\gamma$ expression but also by oxidative alterations in the generation of endogenous PPAR $\gamma$ ligands. The results described in this report show that CCL-2 expression in HUVECs increases in response to AGP and that this increase is associated with an increase in lipid oxidation and PPAR $\gamma$ activation. These changes coincide with a rise in oxidative stress, an increase in 8-isoprostane production, and a decrease in proliferation after treatment with a PPAR $\gamma$ antagonist. There is evidence for increased lipid oxidation, oxidative stress, and PPAR $\gamma$ expression (Kim \& Yang 2013). Using cultured cell models, we demonstrate the existence of an AGP-activated PPAR $\gamma / \mathrm{CCL}-2 / \mathrm{ROS}$ cascade; this cascade explains how a rise in AGP leads to increased oxidative stress and increased PPAR $\gamma$ activation in HUVECs. The increase in ROS results in damage to the cell, including lipid oxidization, GSH depletion, and lipid peroxidation, thus leading to a change or loss of function. The findings of this report indicate that $\mathrm{cPA}$ attenuates the stimulatory effects of AGP on the intracellular function of HUVECs. These findings are consistent with previous reports indicating that the inhibition of PPAR $\gamma$ with cPA in vitro (Tsukahara et al. 2006) and in vivo (Tsukahara et al. 2010) causes reciprocal changes in lipid homeostasis. In conclusion, the results of this study support the working hypothesis that CCL-2 secretion is due in part to an AGP-related increase in CCL-2-mediated lipid oxidation, leading to increased oxidative stress. Because lipid oxidation also plays a fundamental pathogenetic role in atherosclerosis, therapies that target lipoxygenases may be effective in the management of both conditions.

\section{Conflict of interest}

None to declare. 


\section{Funding}

This work was supported by grants from the SENSHIN Medical Research Foundation (2-06 to Tamotsu Tsukahara). The funding source did not have any role in study design; in the collection, analysis and interpretation of data; in writing of the report; or in the decision to submit the article for publication.

\section{Experimental procedures}

\section{Cells, chemicals, and antibodies}

HUVECs were purchased from Promo Cell (C-12203; Heidelberg, Germany) and propagated in endothelial cell growth medium (C-22010) containing 10\% fetal bovine serum (FBS) and antibiotics. cPA18:1 was purchased from Avanti polar lipids (Alabaster, AL, USA). cPA was dissolved in PBS (phosphate-buffered saline) containing $0.1 \%$ fatty acid-free bovine serum albumin (Sigma-Aldrich, St. Louis, MO, USA) to generate a $10 \mathrm{mM}$ stock solution. T0070907 was purchased from Sigma-Aldrich.

\section{Quantitative real-time PCR}

Total RNA was isolated from HUVECs using a NucleoSpin ${ }^{\circledR}$ RNA II Kit (TAKARA, Otsu, Japan). Then, $0.5 \mu \mathrm{g}$ of total RNA was used for cDNA synthesis using a ReverTra Ace qPCR RT Kit (Toyobo) as per the manufacturer's instructions. mRNA levels were quantified using an ECO Real-Time PCR System (Illumina, Inc., San Diego, CA, USA). All PCRs were performed in $10-\mu \mathrm{L}$ volumes in 48 -well PCR plates (Illumina) with GeneAce SYBR qPCR MIX $\alpha$ No ROX (Nippon Gene, Toyama, Japan) and the following primer pairs: PPAR $\gamma, 5^{\prime}-$ GTGGCCGCAGATTTGAAAGAAG-3' (forward) and 5'-TGTCAACCATGGTCATTTCG$3^{\prime}$ (reverse). The glyceraldehyde-3-phosphate dehydrogenase (GAPDH) gene served as an endogenous control. The primers designed to identify the human GAPDH gene were as follows: 5' primer, 5'-GTCGCTGTTGAAGTCAGAGG-3'; and 3' primer, 5'GAAAACTGTGGCGTGATGG-3'. The cycling conditions were as follows: $95^{\circ} \mathrm{C}$ for $10 \mathrm{~min}$ (polymerase activation), followed by 40 cycles of $95^{\circ} \mathrm{C}$ for $15 \mathrm{~s}, 55^{\circ} \mathrm{C}$ for $15 \mathrm{~s}$, and $72^{\circ} \mathrm{C}$ for 
$30 \mathrm{~s}$. After amplification, the samples were slowly heated from $55^{\circ} \mathrm{C}$ to $95^{\circ} \mathrm{C}$ and fluorescence was measured continuously to obtain a melting curve. Relative mRNA levels were quantified using the formula $2^{-\Delta \Delta \mathrm{Cq}}$, where $\Delta \mathrm{Cq}$ is the difference between the threshold cycle of a target cDNA and an endogenous reference cDNA.

\section{Measurement of cell proliferation}

HUVECs were seeded in 96-well culture plates $\left(5 \times 10^{3}\right.$ cells/well), and AGP with or without an T0070907 or cPA was added to cells. After $48 \mathrm{~h}$, cell proliferation was determined using Cell Counting Kit-8 (Dojindo, Kumamoto, Japan). After cells were incubated for 48 h, $10 \mu \mathrm{L}$ of the Cell Counting Kit- 8 solution was added to each well and the plates were incubated for $2 \mathrm{~h}$ in an incubator at $37^{\circ} \mathrm{C}$ with $5 \% \mathrm{CO}_{2}$. The amount of orange formazan dye was determined by measuring absorbance at $450 \mathrm{~nm}$ using a microplate reader (Awareness Technology, Westport, CT, USA).

\section{Western blotting}

Proteins from whole cells were lysed in RIPA buffer (Wako, Tokyo, Japan), separated on 520\% SDS-PAGE gels (e-PAGEL; ATTO, Tokyo, Japan), and electrotransferred to Immobilon-P membranes (Millipore, Burlington, MA, USA). The membranes were blocked in Block Ace (DS Pharma Biomedical Co. Ltd., Osaka, Japan) for $1 \mathrm{~h}$ and then incubated with a primary antibody in TBS-T (Tris-buffered saline-Tween 20) with 5\% Block Ace for $12 \mathrm{~h}$ at $4^{\circ} \mathrm{C}$. Bands were visualized with EzWestLumi plus (ATTO, Amherst, NY, USA) or SuperSignal West Dura (Thermo Fisher Scientific, Waltham, MA, USA).

\section{Small interfering RNAs}

PPAR $\gamma$ expression was suppressed in HUVECs by transfecting the cells with small interfering RNAs (siRNAs) targeting PPAR $\gamma$ (sc-29455; SCBT, CA, USA); the JetPRIME Kit (Polyplustransfection, New York, NY, USA) was used for transfections. Cells were plated in 24-well plates (Iwaki, Tokyo, Japan) at a density of $5 \times 10^{4}$ cells/well in DMEM containing $10 \%$ FBS 
and then transfected with $100 \mathrm{pmol} / \mathrm{mL}$ mRNA-specific siRNAs or scrambled siRNAs (control). Reductions in the expression of PPAR $\gamma$ were confirmed by real-time PCR and western blotting.

\section{ROS production}

HUVECs were seeded in 24-well plates at a density of $5 \times 10^{4}$ cells/well and incubated at $37^{\circ} \mathrm{C}$ for $24 \mathrm{~h}$. Then, the culture medium was aspirated and cells were washed with Dulbecco's PBS (DPBS) followed by the addition of $1 \mathrm{~mL}$ of fresh culture medium containing either DMSO or $10 \mu \mathrm{M}$ carboxy-DCFDA (C-400; Molecular Probes, Eugene, OR, USA). After incubation for $15 \mathrm{~min}, 10 \mu \mathrm{L}$ of DMSO or $10 \mu \mathrm{M}$ carboxy-DCFDA was added to the cells. Hydrogen peroxide $(100 \mu \mathrm{M})$ was used as a positive control stimulus. Following incubation for $60 \mathrm{~min}$, the cells were washed by DPBS and harvested with trypsin-EDTA. Finally, the cells were suspended with $0.3 \mathrm{~mL}$ of $10 \%$ FBS in DPBS and passed through a nylon mesh. Cells were subjected to flow cytometry (FACSCalibur ${ }^{\mathrm{TM}}$; Becton-Dickinson, San Jose, CA, USA) until 20,000 events were recorded.

\section{Determination of total glutathione}

To estimate glutathione, ELISA, enzyme-linked immunosorbent assay was used with a continuous glutathione reductase - catalyzed reduction of 5,5-dithio-bis (2-nitrobenzoic acid) (DTNB) to the chromophore, whose rate was monitored spectrophotometrically at $405 \mathrm{~nm}$ (OxiSelect Total Glutathione (GSSG/GSH) Assay Kit). HUVECs were lysed in $400 \mu \mathrm{L}$ of $5 \%$ sulfosalicylic acid by freeze-thawing. After centrifugation $(10,000 \times g$ for $5 \mathrm{~min})$, the supernatant was transferred to another tube. Then, a $10 \mu \mathrm{L}$ aliquot was mixed with $150 \mu \mathrm{L}$ of potassium phosphate buffer, $\mathrm{pH}$ 7.0, containing $5 \mathrm{mM}$ EDTA, $1.5 \mathrm{mg} / \mathrm{mL}$ DTNB, and 6 $\mathrm{U} / \mathrm{mL}$ glutathione reductase. Finally, $50 \mu \mathrm{L}$ of $(0.16 \mathrm{mg} / \mathrm{mL}) \mathrm{NADPH}$ in potassium phosphate buffer was also added. The absorbance was read at $405 \mathrm{~nm}$ and quantified using microplate reader (Awareness Technology). 


\section{Determination of 8-Isoprostane}

Total 8-iso-prostaglandin (PG) F2 $\alpha$ concentrations were assayed in conditioned medium by a specific enzyme immunoassay (EIA) kit (Cayman Chemical, Ann Arbor, USA). Determine the concentration of each sample using the equation obtained from the standard curve plot. The absorbance was read at $405 \mathrm{~nm}$ and quantified using microplate reader (Awareness Technology). The assay has a range from $0.8-500 \mathrm{pg} / \mathrm{ml}$ and a sensitivity $(80 \% \mathrm{~B} / \mathrm{B} 0)$ of approximately $3 \mathrm{pg} / \mathrm{ml}$. B/B0 curve in competitive enzyme linked immunosorbent assay (ELISA).

\section{Statistical analysis}

The data were analyzed by unpaired Student's $t$-test or one-way ANOVA followed by Newman-Keuls post hoc testing, using GraphPad Prism Ver. 5.01 (GraphPad Software Inc.). The results are expressed as mean $\pm \mathrm{SEM}$.

\section{Author Contributions}

T.T. conceived and designed the project. T.T., S.Y., Y.M., and H.H. acquired the data. T.T. and H.H. analyzed and interpreted the data, and T.T. wrote the article. All authors have read and approved the final version of the article.

\section{References}

Chandra, M., Miriyala, S. \& Panchatcharam, M. (2017) PPARgamma and Its Role in Cardiovascular Diseases. PPAR Res 2017, 6404638.

Davies, S.S. \& Roberts, L.J., 2nd (2011) F2-isoprostanes as an indicator and risk factor for coronary heart disease. Free Radic Biol Med 50, 559-566.

De Rossi, M., Bernasconi, P., Baggi, F., de Waal Malefyt, R. \& Mantegazza, R. (2000) Cytokines and chemokines are both expressed by human myoblasts: possible relevance for the immune pathogenesis of muscle inflammation. Int Immunol 12, 1329-1335. 
Deshmane, S.L., Kremlev, S., Amini, S. \& Sawaya, B.E. (2009) Monocyte chemoattractant protein-1 (MCP-1): an overview. J Interferon Cytokine Res 29, 313-326.

Garcia, N., Zazueta, C. \& Aguilera-Aguirre, L. (2017) Oxidative Stress and Inflammation in Cardiovascular Disease. Oxid Med Cell Longev 2017, 5853238.

Giacco, F. \& Brownlee, M. (2010) Oxidative stress and diabetic complications. Circ Res 107, $1058-1070$.

Girotti, A.W. (1985) Mechanisms of lipid peroxidation. J Free Radic Biol Med 1, 87-95.

Harrington, J.R. (2000) The role of MCP-1 in atherosclerosis. Stem Cells 18, 65-66.

Hwang, J., Kleinhenz, D.J., Lassegue, B., Griendling, K.K., Dikalov, S. \& Hart, C.M. (2005)

Peroxisome proliferator-activated receptor-gamma ligands regulate endothelial membrane superoxide production. Am J Physiol Cell Physiol 288, C899-905.

Kaviarasan, S., Muniandy, S., Qvist, R. \& Ismail, I.S. (2009) F(2)-isoprostanes as novel biomarkers for type 2 diabetes: a review. J Clin Biochem Nutr 45, 1-8.

Kim, T. \& Yang, Q. (2013) Peroxisome-proliferator-activated receptors regulate redox signaling in the cardiovascular system. World J Cardiol 5, 164-174.

Kvandova, M., Majzunova, M. \& Dovinova, I. (2016) The role of PPARgamma in cardiovascular diseases. Physiol Res 65, S343-S363.

Lin, J., Kakkar, V. \& Lu, X. (2014) Impact of MCP-1 in atherosclerosis. Curr Pharm Des 20, $4580-4588$.

Mittal, M., Siddiqui, M.R., Tran, K., Reddy, S.P. \& Malik, A.B. (2014) Reactive oxygen species in inflammation and tissue injury. Antioxid Redox Signal 20, 1126-1167. 
Mylonas, C. \& Kouretas, D. (1999) Lipid peroxidation and tissue damage. In Vivo 13, 295309.

Nagy, L., Tontonoz, P., Alvarez, J.G., Chen, H. \& Evans, R.M. (1998) Oxidized LDL regulates macrophage gene expression through ligand activation of PPARgamma. Cell $\mathbf{9 3}$, 229-240.

Nobs, S.P., Natali, S., Pohlmeier, L., Okreglicka, K., Schneider, C., Kurrer, M., Sallusto, F. \& Kopf, M. (2017) PPARgamma in dendritic cells and T cells drives pathogenic type-2 effector responses in lung inflammation. $J$ Exp Med 214, 3015-3035.

Panzer, U., Schneider, A., Guan, Y., Reinking, R., Zahner, G., Harendza, S., Wolf, G., Thaiss, F. \& Stahl, R.A. (2002) Effects of different PPARgamma-agonists on MCP-1 expression and monocyte recruitment in experimental glomerulonephritis. Kidney Int 62, 455-464.

Reape, T.J. \& Groot, P.H. (1999) Chemokines and atherosclerosis. Atherosclerosis 147, $213-$ 225.

Shao, B. \& Heinecke, J.W. (2009) HDL, lipid peroxidation, and atherosclerosis. J Lipid Res 50, 599-601.

Tontonoz, P., Hu, E., Graves, R.A., Budavari, A.I. \& Spiegelman, B.M. (1994) mPPAR gamma 2: tissue-specific regulator of an adipocyte enhancer. Genes Dev 8, 1224-1234. Tsukahara, T. \& Haniu, H. (2012) Lysophosphatidic Acid Stimulates MCP-1 Secretion from C2C12 Myoblast. ISRN Inflamm 2012, 983420.

Tsukahara, T., Haniu, H. \& Matsuda, Y. (2013) Effect of alkyl glycerophosphate on the activation of peroxisome proliferator-activated receptor gamma and glucose uptake in $\mathrm{C} 2 \mathrm{C} 12$ cells. Biochem Biophys Res Commun 433, 281-285. 
Tsukahara, T., Tsukahara, R., Fujiwara, Y. et al. (2010) Phospholipase D2-dependent inhibition of the nuclear hormone receptor PPARgamma by cyclic phosphatidic acid. Mol Cell 39, 421-432.

Tsukahara, T., Tsukahara, R., Yasuda, S., Makarova, N., Valentine, W.J., Allison, P., Yuan, H., Baker, D.L., Li, Z., Bittman, R., Parrill, A. \& Tigyi, G. (2006) Different residues mediate recognition of 1-O-oleyllysophosphatidic acid and rosiglitazone in the ligand binding domain of peroxisome proliferator-activated receptor gamma. J Biol Chem 281, 3398-3407.

Turner, M.D., Nedjai, B., Hurst, T. \& Pennington, D.J. (2014) Cytokines and chemokines: At the crossroads of cell signalling and inflammatory disease. Biochim Biophys Acta 1843, 25632582.

Verma, S. \& Szmitko, P.E. (2006) The vascular biology of peroxisome proliferator-activated receptors: modulation of atherosclerosis. Can J Cardiol 22 Suppl B, 12B-17B.

Volp, A.C., Alfenas Rde, C., Costa, N.M., Minim, V.P., Stringueta, P.C. \& Bressan, J. (2008) [Inflammation biomarkers capacity in predicting the metabolic syndrome]. Arq Bras Endocrinol Metabol 52, 537-549.

Wang, Y. \& Tabas, I. (2014) Emerging roles of mitochondria ROS in atherosclerotic lesions: causation or association? J Atheroscler Thromb 21, 381-390.

Wu, G., Fang, Y.Z., Yang, S., Lupton, J.R. \& Turner, N.D. (2004) Glutathione metabolism and its implications for health. $J$ Nutr 134, 489-492.

Zhang, C., Baker, D.L., Yasuda, S., Makarova, N., Balazs, L., Johnson, L.R., Marathe, G.K., McIntyre, T.M., Xu, Y., Prestwich, G.D., Byun, H.S., Bittman, R. \& Tigyi, G. (2004) Lysophosphatidic acid induces neointima formation through PPARgamma activation. $J$ Exp Med 199, 763-774. 


\section{Figure Legends}

\section{Figure 1.}

(A) Real-time PCR analysis of the expression of $P P A R \gamma_{1}$ and $P P A R \gamma_{2}$ mRNA in HUVECs. Relative mRNA levels of $P P A R \gamma_{1}$ and $P P A R \gamma_{2}$ normalized to GAPDH are expressed as means \pm standard error of the mean $\left(\mathrm{n}=3,{ }^{* *} p<0.01\right)$. (B) Western blot analysis of the expression of PPAR $\gamma_{1}$ and PPAR $\gamma_{2}$ in HUVECs. (C) HUVECs were transfected with the PPRE-luc and CMV- $\beta$-galactosidase plasmids for $72 \mathrm{~h}$ and then treated with the indicated compounds for 24 h. Luciferase activity was measured in cell lysates and normalized to $\beta$-galactosidase activity. Data represent means \pm standard error of the mean $\left(\mathrm{n}=3,{ }^{* *} p<0.01\right.$, \&\& $p<0.01,{ }^{\#} p<0.01$,

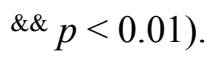

\section{Figure 2.}

cPA inhibited AGP-mediated CCL-2 expression and production in HUVECs (A) HUVECs were treated with the indicated compounds for $24 \mathrm{~h}$. Real-time PCR analysis of the expression of CCL-2 mRNA in HUVECs. LPS (10 ng/ml) was used as a positive control. Relative mRNA levels of $C C L-2$ normalized to $G A P D H$ are expressed as means \pm standard error of the mean $\left(\mathrm{n}=3,{ }^{* *} p<0.01\right)$. (B) Real-time PCR analysis of PPAR $\gamma$ mRNA expression in HUVECs. Relative PPAR $\gamma$ levels normalized to $G A P D H$ are expressed as means $\pm \mathrm{SEM}(\mathrm{n}=3$, ${ }^{* *} p<0.01$ ). (C) Total protein was extracted from control siRNA-transfected or PPAR $\gamma$ siRNA-transfected cells. Twenty-four hours later, whole-cell lysates were analyzed by western blotting using specific antibodies against PPAR $\gamma$. Incubation with an anti- $\beta$-actin antibody was used as a protein-loading control. (D) $C C L-2$ mRNA expression was reduced in cPA and PPAR $\gamma$ siRNA-transfected HUVECs. Relative mRNA levels of CCL-2 normalized to $G A P D H$ are expressed as means \pm standard error of the mean $\left(\mathrm{n}=3,{ }^{* *} p<0.01\right)$. (E) CCL2 secretion was decreased in cPA and PPAR $\gamma$ siRNA-transfected HUVECs. Data represent means \pm standard error of the mean $\left(\mathrm{n}=3,{ }^{* *} p<0.01\right)$. 


\section{Figure 3.}

(A) AGP-mediated ROS production in HUVECs. ROS production was increased upon treatment with AGP $(1,3$, and $10 \mu \mathrm{M})$ and this secretion was attenuated by PPAR $\gamma$ antagonists T0070907 and cPA. BHA $(50 \mu \mathrm{M})$ and $\mathrm{H}_{2} \mathrm{O}_{2}(50 \mu \mathrm{M})$ were used as positive control. Data represent means \pm standard error of the mean $\left(\mathrm{n}=3,{ }^{* *} p<0.01,{ }^{\#} p<0.01,{ }^{\$ \$} p\right.$ $<0.01)$. (B) AGP depleted intracellular reduced glutathione (GSH) in a dose-dependent manner. GSH production was decreased upon treatment with $\operatorname{AGP}(1,3$, and $10 \mu \mathrm{M})$ and this depletion was inhibited by PPAR $\gamma$ antagonists T0070907 $(1 \mu \mathrm{M})$ and $\mathrm{cPA}(10 \mu \mathrm{M})$. The absorbance was read at $405 \mathrm{~nm}$ and quantified using microplate reader. Data represent means \pm standard error of the mean $\left(\mathrm{n}=3,{ }^{* *} p<0.01\right)$.

\section{Figure 4.}

(A) AGP mediated 8-isoprostane production in HUVECs. AGP significantly increased 8isoprostane production in a dose-dependent manner and this production was attenuated by PPAR $\gamma$ antagonists T0070907 $(1 \mu \mathrm{M})$ and cPA $(10 \mu \mathrm{M})$. The absorbance was read at $405 \mathrm{~nm}$ and quantified using microplate reader. Data represent means \pm standard error of the mean (n $=3,{ }^{* *} p<0.01$ ). (B) Effects of combination treatments with a PPAR $\gamma$ agonist and antagonist. The medium was replaced with fresh medium, and AGP with or without an antagonist was added to cells. After $48 \mathrm{~h}$, cell proliferation was determined using Cell Counting Kit-8. Ten microliters of Cell Counting Kit- 8 were added to the medium and incubated for $2 \mathrm{~h}$ in a $5 \%$ $\mathrm{CO}_{2}$ incubator. The absorbance was read at $600 \mathrm{~nm}$ and quantified using microplate reader.

Data are presented as means $\pm \operatorname{SEM}(\mathrm{n}=3),{ }^{* *} p<0.01,{ }^{\# \#} p<0.01$ 
A

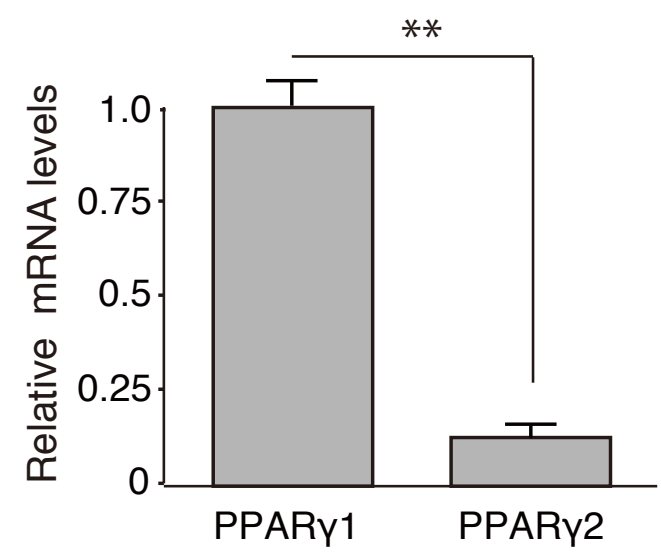

B

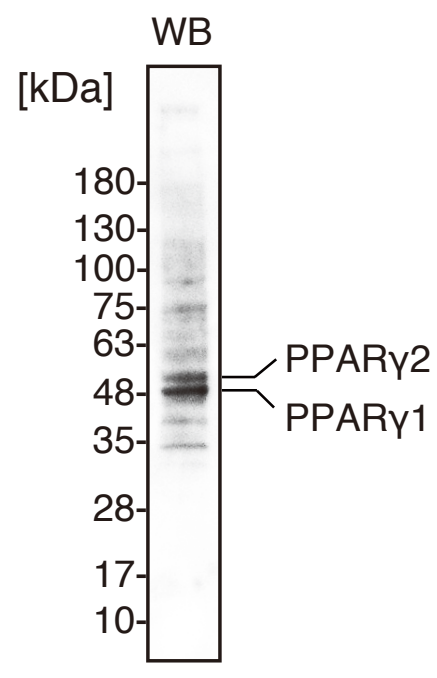

anti-PPARy ab

C
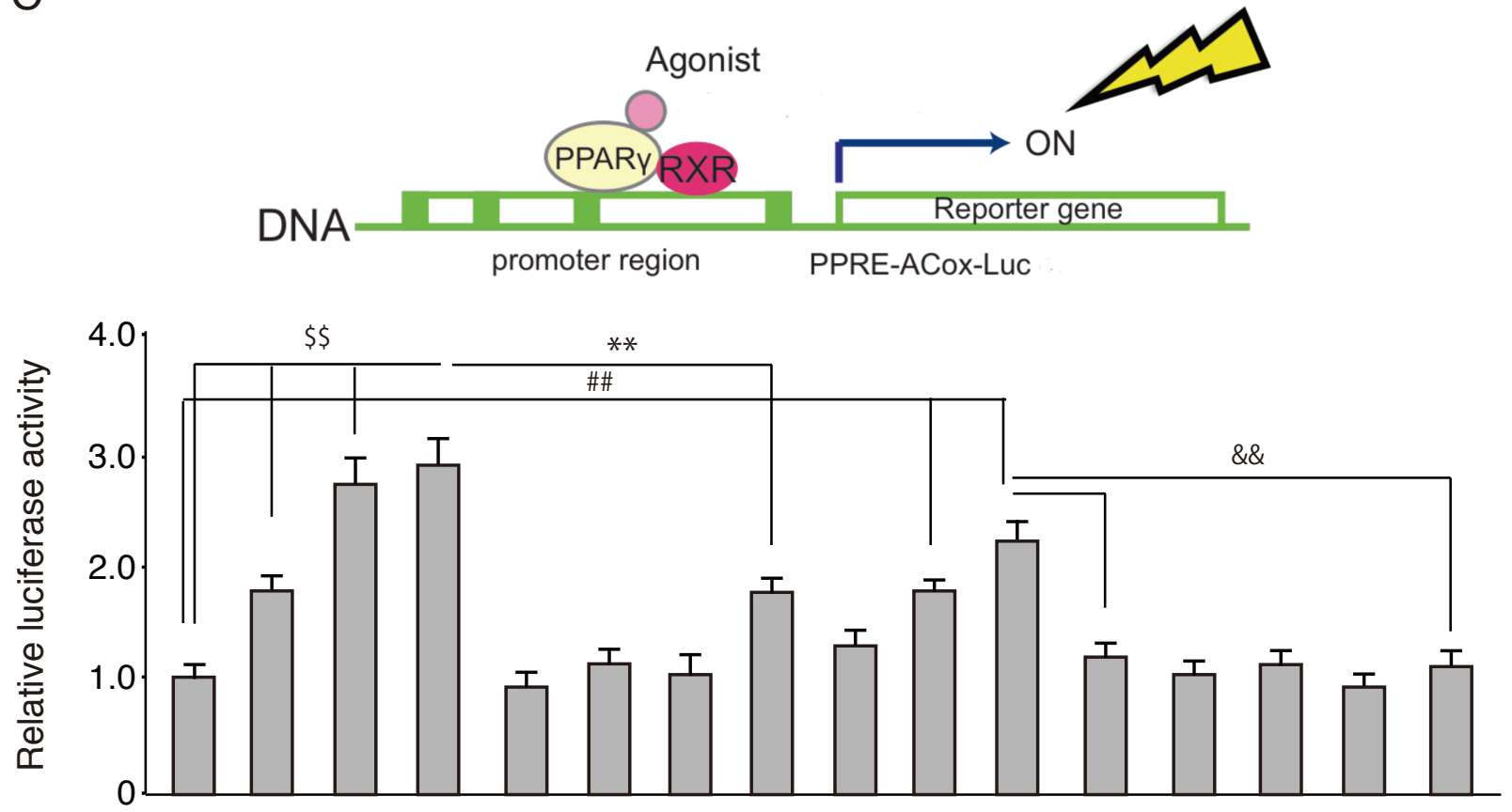

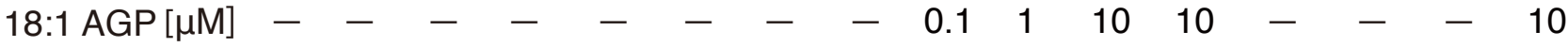

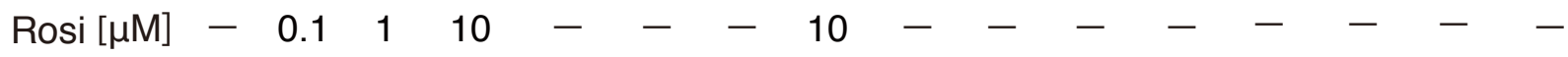

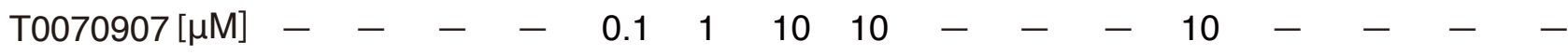

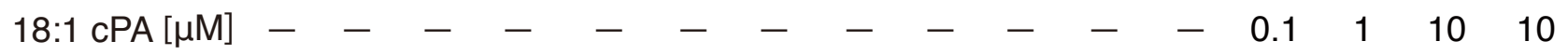

Fig. 1 
A

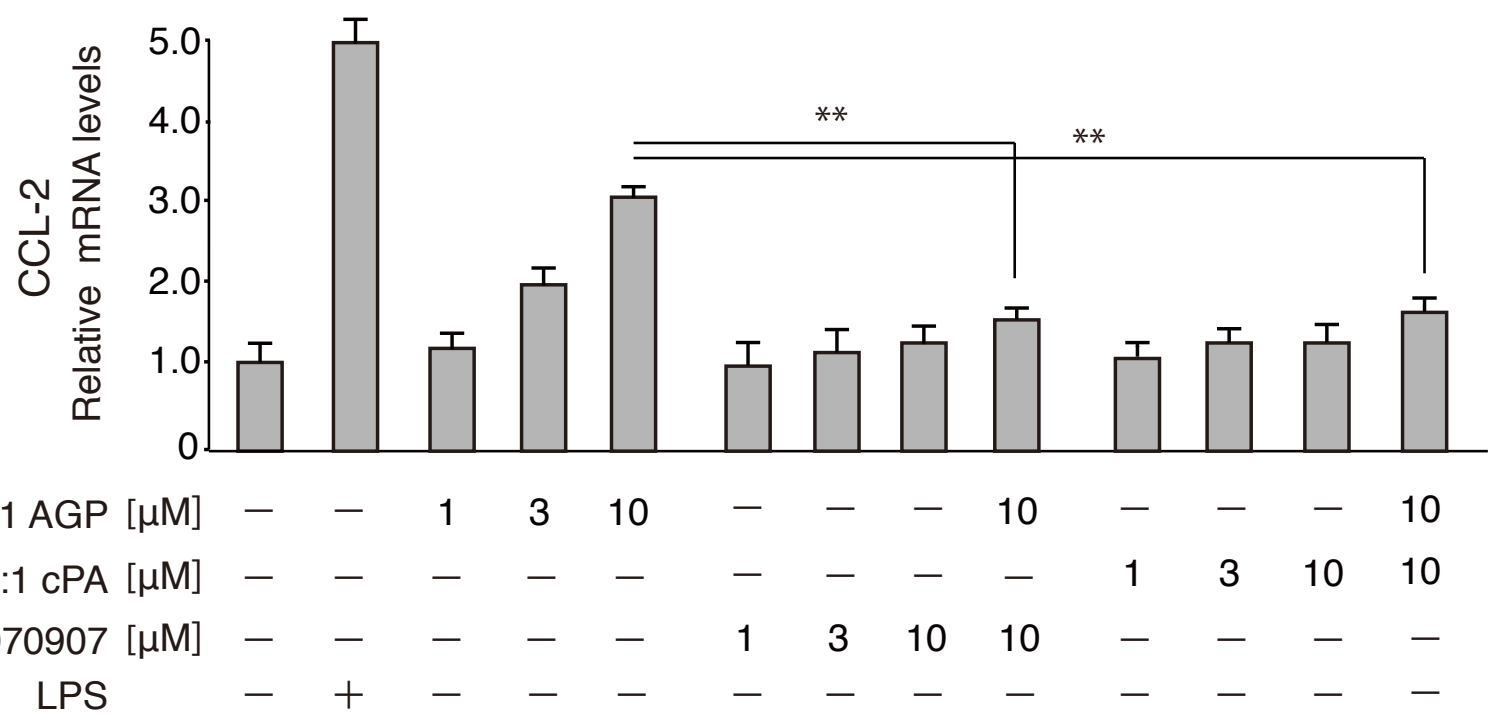

B

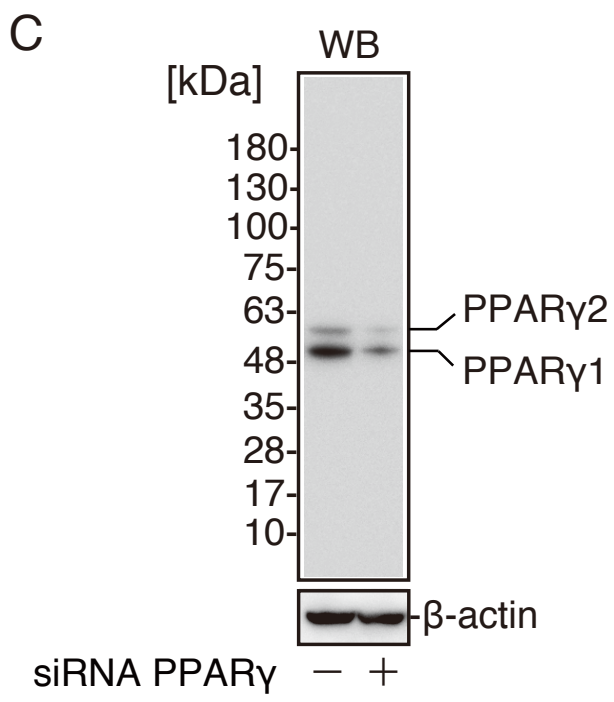

D

E

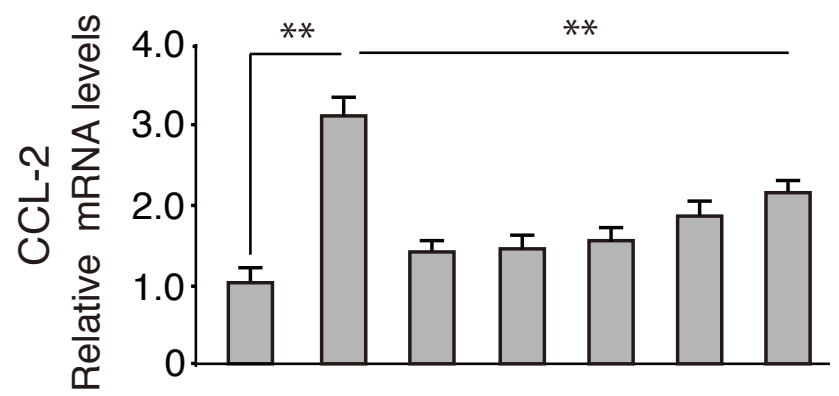

18:1 AGP $[\mu \mathrm{M}] \quad-\quad 10-0.1 \quad 1 \quad 10 \quad 10$

SIRNA PPARY $-\quad-++++-$

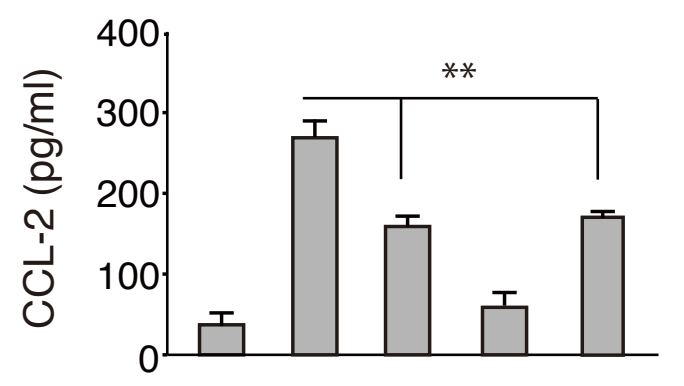

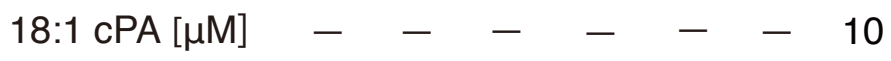

18:1 AGP $[\mu \mathrm{M}] \quad-\quad \begin{array}{llll}10 & 10 & - & 10\end{array}$

SIRNA PPARY $-\quad-++-$

18:1 $\mathrm{cPA}[\mu \mathrm{M}]-\quad-\quad-\quad 10$

Fig.2 
A

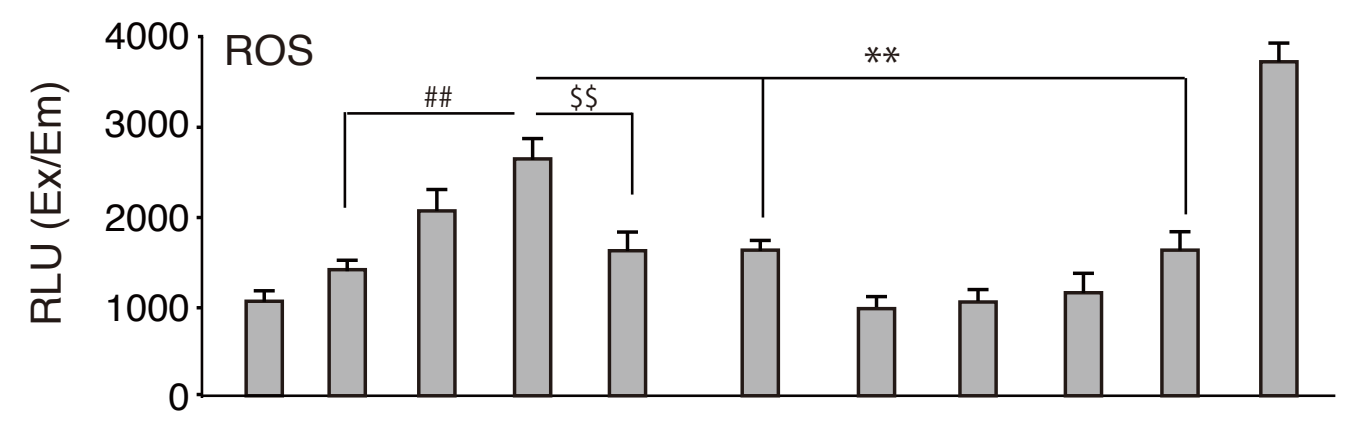

\begin{tabular}{|c|c|c|c|c|c|c|c|c|c|c|c|}
\hline 18:1 AGP[ $\mu \mathrm{M}]$ & - & 1 & 3 & 10 & 10 & 10 & - & - & - & 10 & \\
\hline 18:1 cPA [ $\mu \mathrm{M}]$ & - & - & - & - & - & - & 1 & 3 & 10 & 10 & - \\
\hline T0070907 [uM] & - & - & - & - & - & 1 & - & - & - & - & - \\
\hline $\mathrm{BHA}[\mu \mathrm{M}]$ & - & - & - & - & 50 & - & - & - & - & - & - \\
\hline $\mathrm{H}_{2} \mathrm{O}_{2}[\mu \mathrm{M}]$ & - & - & - & - & - & - & - & - & - & - & 50 \\
\hline
\end{tabular}

B

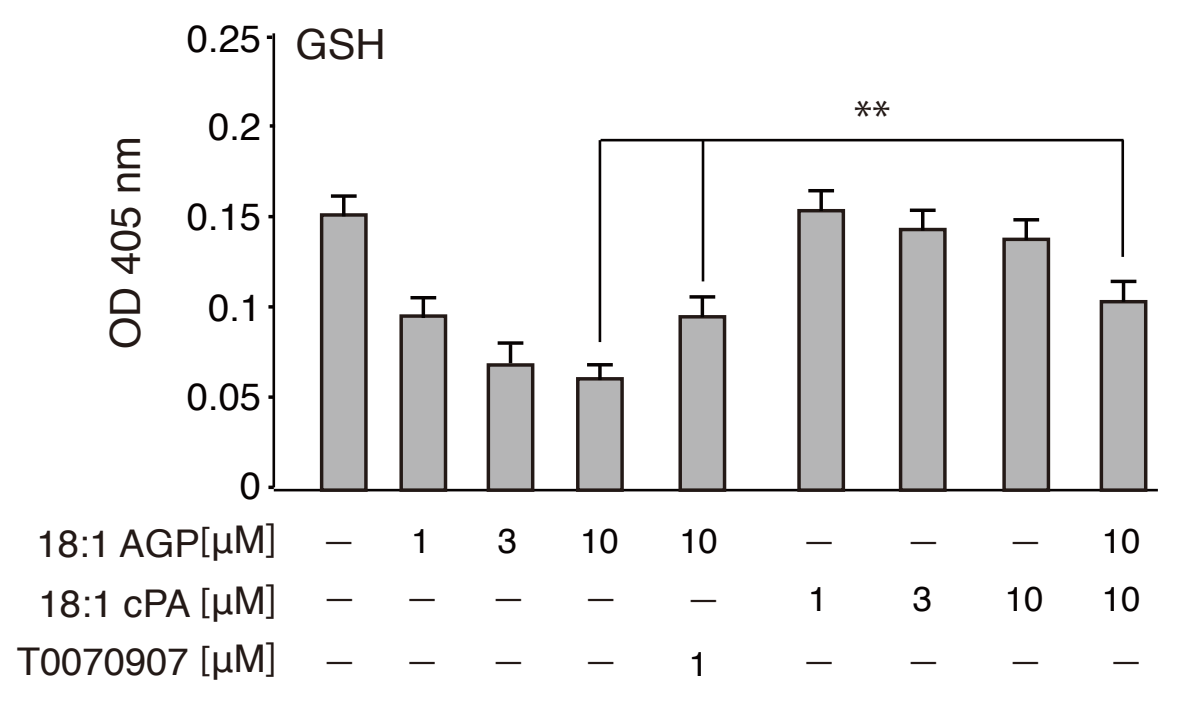

Fig.3 
A

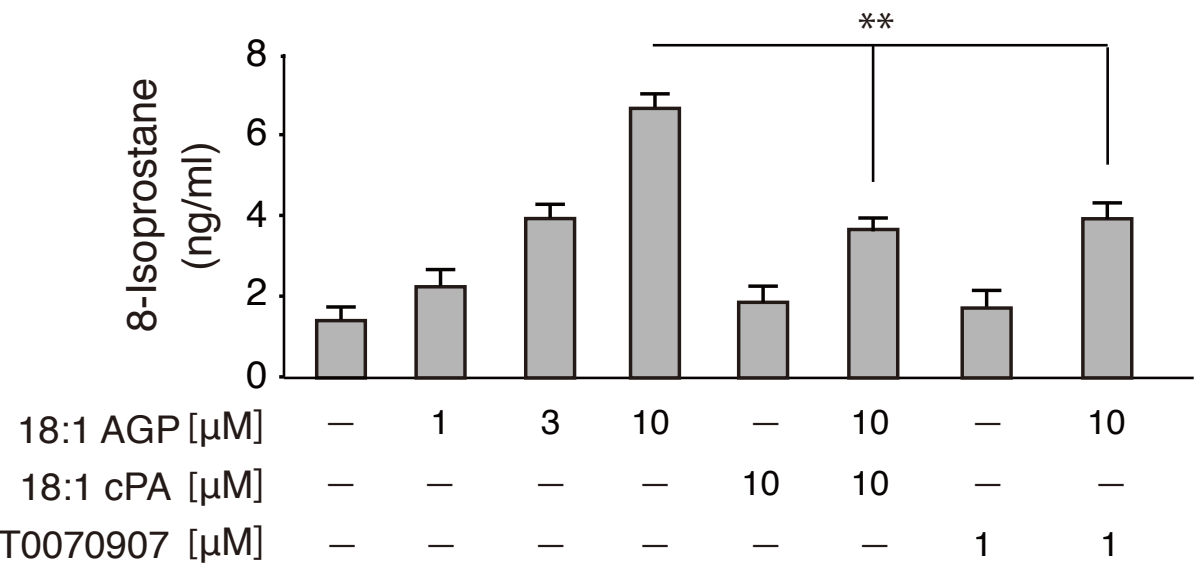

B

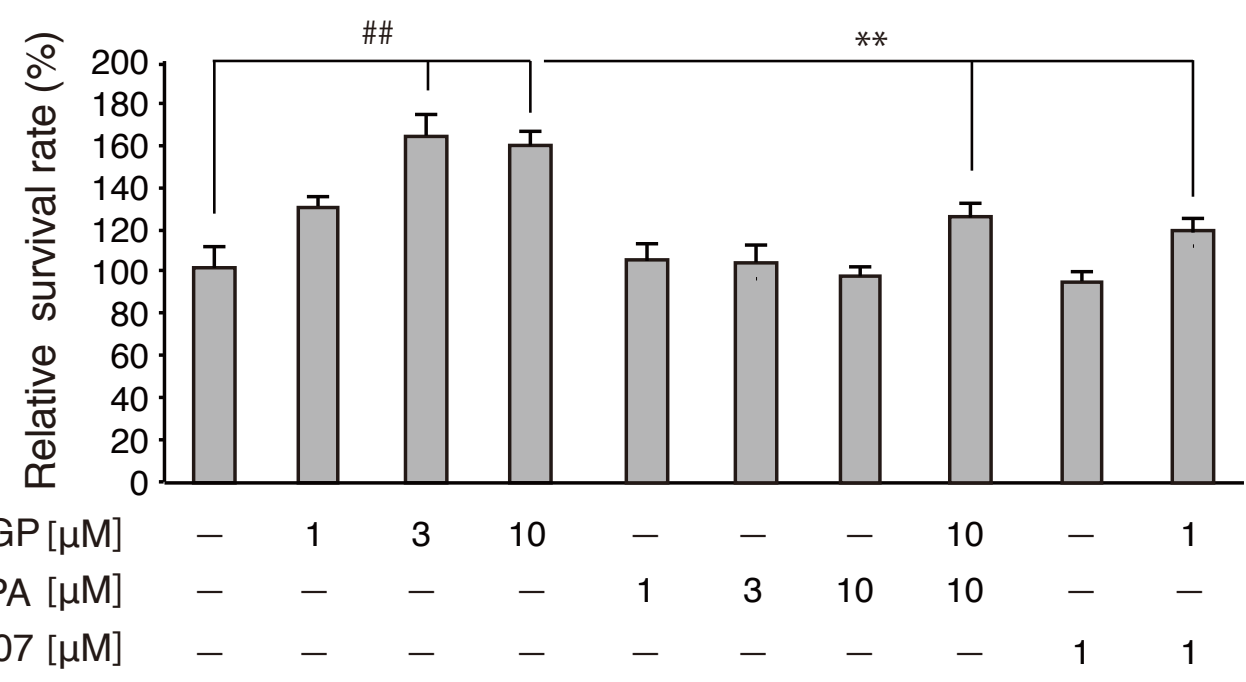

Fig.4 